\title{
Spatial analysis of mandibular condyles in patients with temporomandibular disorders and normal controls using cone beam computed tomography
}

\author{
Natheer Hashim Al-Rawi ${ }^{1}$, Asmaa Tahseen Uthman², Sahar M. Sodeify ${ }^{3}$
}

Correspondence: Dr. Natheer Hashim Al-Rawi

Email: nhabdulla@sharjah.ac.ae

\begin{abstract}
'Department Oral Health Sciences, College of Dental Medicine, University of Sharjah, Sharjah, UAE,

${ }^{2}$ Department of Oral Medicine and Radiology, Gulf Medical University, Ajman, UAE,

${ }^{3}$ Department of Preventive and Restorative Dentistry, College of Dental Medicine, University of Sharjah, Sharjah, UAE
\end{abstract}

\section{ABSTRACT}

Objectives: The aim of the study is to investigate the condylar position and its relation to articular eminence and axial condylar angle in temporomandibular joint disorder (TMD) patients and in normal controls using cone beam computed tomography (CBCT). Materials and Methods: CBCT temporomandibular joint (TMJ) images of 70 participants (38 males and 32 females, mean age 26.4 years) were analyzed. They were divided into control group (including 35 subjects) and study group (including 35 subjects). Linear measurements of joint space and condyle determined the condylar position of each TMJ. Articular eminence height and inclination were also measured with axial condylar angle to determine its relation to condylar position. Independent and paired sample $t$-test was applied to compare between the groups and TMJ sides of the same group at significance level of 0.05. Results: Statistical significant differences were found between males and females of both groups regarding superior joint space (SJS), lateral joint space, A-P, and M-L condyle distance $(P<0.05)$. SJS, medial joint space (MJS), and eminence angle were greater $(P<0.01)$ in male's joints with TMD with flatter axial condylar angle $(P<0.05)$, when compared with normal TMJ counterpart. Females TMJs showed significantly higher values of MJS of affected side when compared with normal counterpart with flatter axial condylar angle $(P<0.05)$. Conclusion: Superior and MJS parameters were the ones that showed significant differences between affected and nonaffected joints. The mean axial condylar angle was smaller in joints with abnormal TMJ. This indicates that the condyles of the affected joints may rotate inward.

Key words: Articular eminence, condylar angle, cone beam computed tomography, joint space, temporomandibular joint

\section{INTRODUCTION}

The mandibular condyle varies greatly in different groups and individuals; this might be due to developmental variability or condylar remodeling. The anterior limit of the glenoid fossa is convex in shape and is formed by the articular eminence. ${ }^{[1,2]}$ The inclination of articular eminence varies in peoples; it determines

\begin{tabular}{|l|l|}
\hline \multicolumn{2}{|c|}{ Access this article online } \\
\hline Quick Response Code: \\
\hline
\end{tabular}

the path of condylar movement as well as the degree of rotation of the disc over the condyle. ${ }^{[3,4]}$ Researches are continued to find the best method for detecting the ideal position of condyle in glenoid fossa. This would assess

This is an open access article distributed under the terms of the Creative Commons Attribution-NonCommercial-ShareAlike 3.0 License, which allows others to remix, tweak, and build upon the work non-commercially, as long as the author is credited and the new creations are licensed under the identical terms.

For reprints contact: reprints@medknow.com

How to cite this article: Al-Rawi NH, Uthman AT, Sodeify SM. Spatial
analysis of mandibular condyles in patients with temporomandibular
disorders and normal controls using cone beam computed tomography.
Eur J Dent 2017;11:99-105.
DOI: $10.4103 /$ ejd.ejd_202_16


temporomandibular joint disorder (TMD), and the most predictable approach is by measurement of dimension of joint space. The joint space describes the radiolucent zone between condylar and temporal bony parts. ${ }^{[5,6]}$ The clinical significance of condylar-fossa relationships in the temporomandibular joint (TMJ) is controversial. ${ }^{[7]}$ Some studies proposed an association between eccentric condylar position and TMD. ${ }^{[8,9]}$ However, other studies failed to demonstrate a significant association between the condylar position and the incidence of TMD.$^{[10,11]}$ Although little information can be retrieved about the TMJ bony structures, magnetic resonance imaging (MRI) is still the most useful tool to show disc displacement. ${ }^{[6]}$ The aim of this study is to assess TMJ space among people with normal TMJ function and those with temporomandibular disorders through images by cone beam computed tomography (CBCT) and to find the relationship between measurements of articular eminence height (EH), inclination angle, and axial condylar angle.

\section{MATERIALS AND METHODS}

The research was approved by the Research Ethics Committee of University of Sharjah, College of Dental Medicine. Every patient's written consent has been also checked before imaging in our faculty. A total number of records and CBCT were 211. Seventy patients met our inclusion criteria, which were with age range between 16 and 44 and with full dentition. They were divided into two groups of study and control. The control group included 35 patients ( 19 males and 16 females between 16 and 38 years of age with an average age of 24.7 years) with no history of TMD. The absence of TMD was described as following: lack of pain or discomfort in joint, clicking, crepitation, clenching, absence of any limitation of mouth opening, or deviation. The study group included 35 patients (19 males and 16 females between 16 and 44 years of age with an average age of 27.9 years). The patients who were included in the study group were selected according to the Research Diagnostic Criteria for Temporomandibular joint Disorders (RDC/TMD) guidelines (Groups IIa, IIb, IIc, and III) ${ }^{[12]}$ as confirmed by MRI. All CBCT images were taken during the first visit of the patient to Oral Diagnosis Department at University of Sharjah, College of Dental Medicine using GALILEOS 3D X-ray system (SIRONA Dental System, USA). Similar exposure parameters were used for all patients; tube voltage: $85 \mathrm{kV}$, tube current: $7 \mathrm{~mA}$, exposure duration: $13 \mathrm{~s}$, effective dose: $75 \mathrm{mV}$, voxel size: $150 \mu \mathrm{m}$ (screen resolution $1366 \times 768)$, and the slice thickness was $1.0 \mathrm{~mm}$ with edge-to-edge jaw relationship. Image interpretation and measurements were done by an oral and maxillofacial radiologist. At first, slices from the sagittal sections were evaluated where the anteroposterior diameter of the right and left condyle was the greatest.

The standardized linear measurements of space between condyle and the articular fossa were done in accordance with Ikeda and Kawamura. ${ }^{\left[{ }^{[8}\right.}$

From reconstructed sagittal sections, two horizontal lines were drawn; the first one is tangent to the uppermost area of the glenoid fossa (A) and parallel to Frankfort horizontal plane. The second line was drawn tangent to the most superior surface of the condyle (B). Two other lines were drawn tangential to the most anterior surface (D) and to the most posterior surface (E) of the condyle. A perpendicular distance between $\mathrm{A}$ and $\mathrm{B}, \mathrm{C}$ and $\mathrm{D}$, and $\mathrm{E}$ and $\mathrm{F}$ were then measured and considered as superior joint space (SJS), anterior joint space, and posterior joint space (PJS) distances, respectively [Figure 1]. Medial joint space (MJS) and lateral joint space (LJS) were measured from reconstructed coronal sections; the most prominent point on medial (M) and lateral (L) poles of the head of the condyle were first identified. Two tangential lines were then drawn on medial and lateral slopes of the glenoid fossa. A perpendicular distance between $\mathrm{M}$ point and the medial tangent and between $L$ point and lateral tangent was measured as MJS and LJS distances, respectively [Figure 2].

The axial condylar angle was also measured, and it is defined as the angle between thelong axis of the condylar process and a perpendicular line to the midsagittal plane in the axial view [Figure 3]. For articular

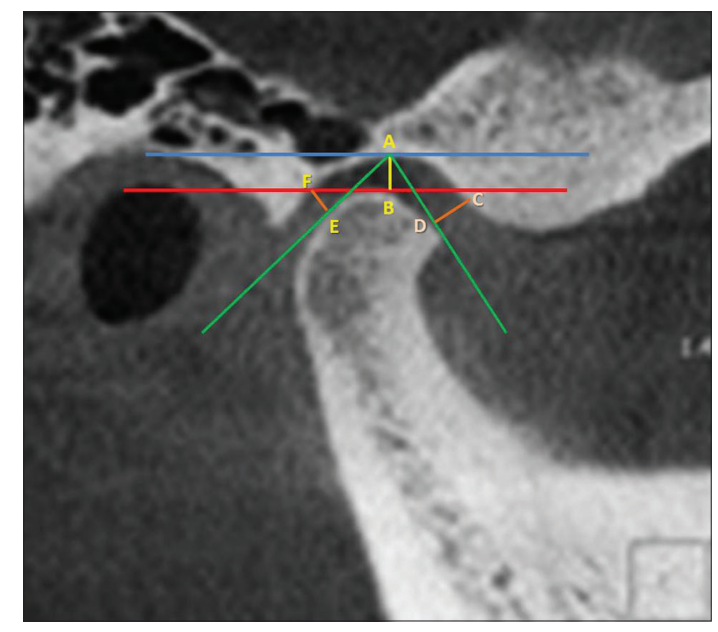

Figure 1: Measurement of anterior joint space, posterior joint space, and superior joint space (from sagittal view) 
eminence inclination and height measurements, the widest mediolateral condylar process was used as a reference sagittal view for secondary reconstruction. The EH was measured by the perpendicular distance between the lowest point of the articular eminence and the highest point of the glenoid fossa on central sagittal slice [Figure 4]. For articular eminence inclination, a line connecting the most superior point (S) of the glenoid fossa with the most inferior point of articular eminence was drawn. The intersection of this line with the Frankfort horizontal line made the articular eminence angle [Figure 4]..$^{[9]}$

All measurements were repeated after 2 weeks by the same investigator, and the mean of the 2 measurements was used in the statistical analysis. The mean values for all the measurements on the right and left sides were considered as the total measurements. Accordingly, $\mathrm{P} / \mathrm{A}$ ratio, S/A ratio, and $\mathrm{M} / \mathrm{L}$ ratio were also calculated. ${ }^{[6]}$

A paired sample $t$-test was used to identify the significance of differences in joint spaces dimensions of the right and the left sides of the same subject. Independent sample $t$-test was also used to identify the significance of differences between genders and between normal and abnormal TMJ. $P<0.05$ was considered statistically significant using IBM, SPSS version 21 (Chicago, IL, USA).

\section{RESULTS}

In this study, CBCT images of 70 patients ( 35 with TJD and 35 without any history of TMD) were assessed. It was found that only left AJS of control and study groups was significantly smaller than that of the right side $(P<0.01)$ as shown in Tables 1 and 2 .

All values for SJS, LJS, and M-L distance were significantly $(P<0.05)$ greater in male for both normal and study groups. Females had flatter condylar angle comparing to male, especially in control group. Eminence angle of female group was found to have lesser values when compared with that of male group $(P<0.05)$ [Tables 3 and 4]. Using paired $t$-test to measure the difference in the mean values of the studied parameters, SJS and MJS were significantly greater in the affected joints when compared with the normal counterpart of male group. Eminence angle was significantly greater in the affected joints $\left(40.78^{\circ} \pm 10.57^{\circ}\right.$ vs. $\left.30.01^{\circ} \pm 9.39^{\circ}\right)$, whereas, condylar angle was flatter in the affected joint $\left(18.36^{\circ} \pm 5.1^{\circ} \mathrm{vs}\right.$. $23.18^{\circ} \pm 5.47^{\circ}$ ) [Table 5].

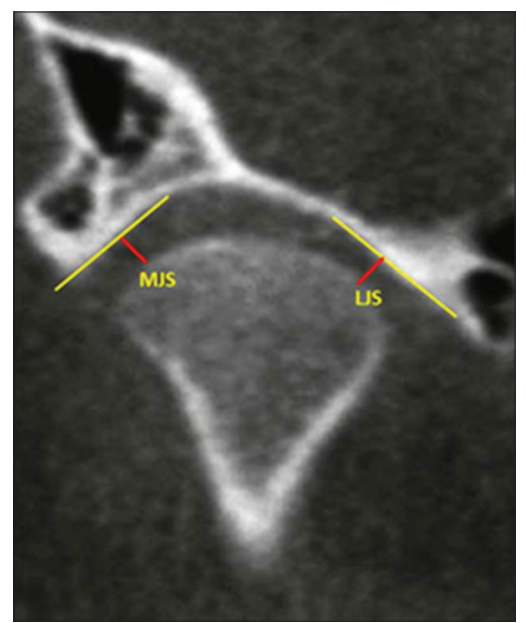

Figure 2: Measurement of medial joint space and lateral joint space (coronal cone beam computed tomography view)

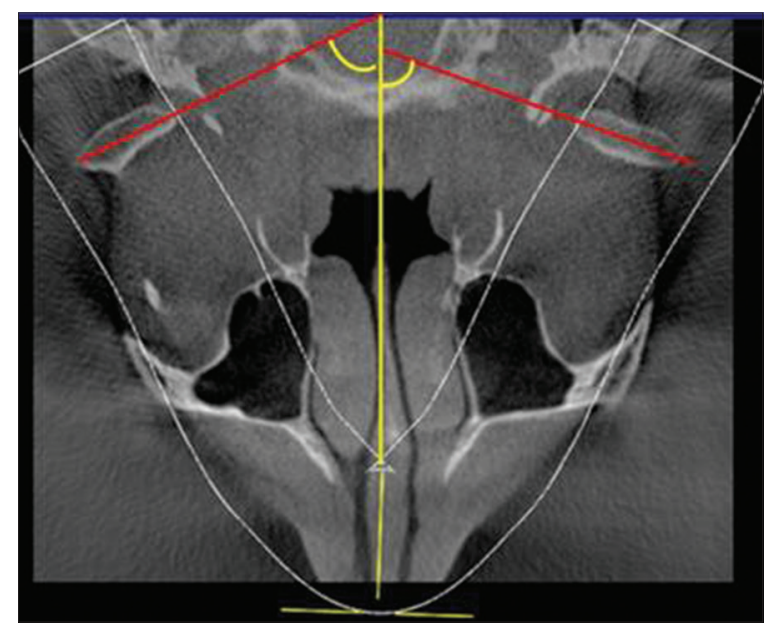

Figure 3: Measurement of axial condylar angle (axial cone beam computed tomography view)

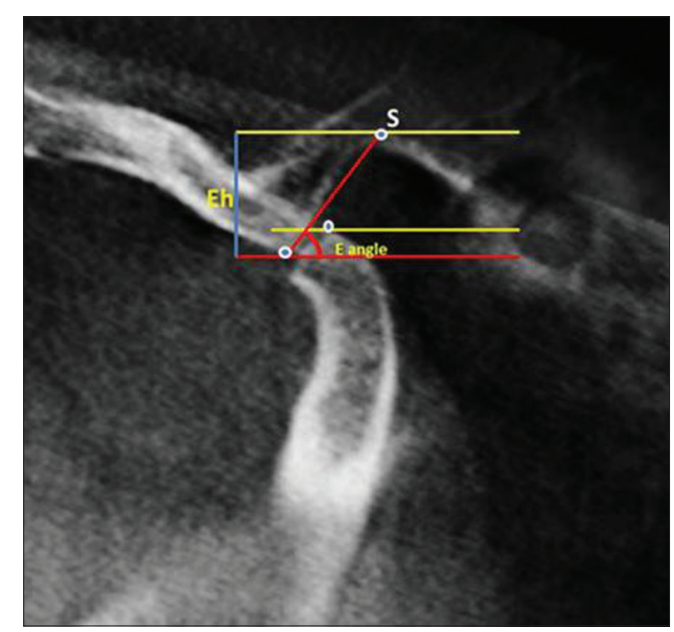

Figure 4: Method of eminence height and eminence angle measurement (sagittal cone beam computed tomography view)

In female group, MJS was the only parameter among joint spaces that showed a significant increase in 


\begin{tabular}{|c|c|c|c|c|c|}
\hline Joint space & Right side (35), mean $\pm S D$ & Range & Left side (35), mean $\pm S D$ & Range & $P$ \\
\hline$\overline{\text { AJS }}$ & $2.4 \pm 0.77$ & $1.09-4.34$ & $1.79 \pm 0.7$ & $0.0-3.14$ & $0.001^{* \star}$ \\
\hline SJS & $5.45 \pm 1.87$ & $1.3-11.23$ & $5.44 \pm 1.63$ & $2.46-8.47$ & 0.986 \\
\hline PJS & $5.88 \pm 2.84$ & $2.02-13.55$ & $6.62 \pm 2.44$ & $1.26-11.12$ & 0.83 \\
\hline MJS & $5.28 \pm 2.28$ & $1.82-10.71$ & $5.43 \pm 1.8$ & $2.24-9.59$ & 0.774 \\
\hline LJS & $3.00 \pm 1.11$ & $0.95-5.37$ & $2.96 \pm 1.3$ & $0.0-6.6$ & 0.893 \\
\hline $\mathrm{P} / \mathrm{A}$ & $2.60 \pm 1.4$ & & $3.24 \pm 1.75$ & & 0.08 \\
\hline S/A & $2.51 \pm 1.23$ & & $3.08 \pm 1.39$ & & $0.006^{\star *}$ \\
\hline$M / L$ & $2.04 \pm 1.26$ & & $2.02 \pm 0.86$ & & 0.69 \\
\hline A-P distance & $7.01 \pm 1.4$ & $4.34-9.39$ & $6.96 \pm 1.24$ & $4.64-10.15$ & 0.879 \\
\hline M-L distance & $16.98 \pm 2.2$ & $7.39-24.07$ & $18.0 \pm 2.95$ & $11.15-23.45$ & 0.128 \\
\hline Eminence height & $7.44 \pm 1.67$ & $3.74-11.17$ & $7.42 \pm 2.21$ & $0.0-10.67$ & 0.96 \\
\hline Eminence angle & $39.71 \pm 8.58$ & $22.1-57.1$ & $38.98 \pm 7.95$ & $18.4-54$ & 0.98 \\
\hline Condylar angle & $19.09 \pm 9.61$ & $12.6-37.7$ & $19.03 \pm 9.02$ & $9.5-38$ & 0.738 \\
\hline
\end{tabular}

Significant difference $\left.{ }^{* \star} P \leq 0.01\right)$. AJS: Anterior joint space, SJS: Superior joint space, PJS: Posterior joint space, MJS: Medial joint space, LJS: Lateral joint space, SD: Standard deviation

\begin{tabular}{|c|c|c|c|c|c|}
\hline Joint space & Right side (35), mean $\pm S D$ & Range & Left side (35), mean $\pm S D$ & Range & $P$ \\
\hline AJS & $2.34 \pm 0.94$ & $0.0-4.87$ & $1.86 \pm 1.03$ & $0.0-3.88$ & $0.04^{*}$ \\
\hline SJS & $4.93 \pm 1.75$ & $1.89-8.3$ & $5.24 \pm 1.92$ & $1.96-10.96$ & 0.481 \\
\hline PJS & $5.42 \pm 1.99$ & $2.4-11.26$ & $6.14 \pm 2.93$ & $1.27-13.36$ & 0.225 \\
\hline MJS & $4.23 \pm 1.69$ & $2.04-9.0$ & $4.90 \pm 1.85$ & $1.5-8.78$ & 0.113 \\
\hline LJS & $2.98 \pm 1.48$ & & $3.27 \pm 1.36$ & $1.25-7.33$ & 0.526 \\
\hline P/A & $2.47 \pm 1.19$ & & $3.08 \pm 2.29$ & & 0.10 \\
\hline S/A & $2.24 \pm 0.98$ & & $2.7 \pm 1.33$ & & 0.06 \\
\hline$M / L$ & $1.69 \pm 1.01$ & & $1.75 \pm 1.06$ & & 0.90 \\
\hline A-P distance & $7.32 \pm 1.29$ & $4.94-10.6$ & $7.11 \pm 1.25$ & $3.89-10.32$ & 0.526 \\
\hline M-L distance & $18.49 \pm 3.2$ & $10.81-23.39$ & $18.23 \pm 3.6$ & $11.15-25.69$ & 0.751 \\
\hline Eminence height & $7.89 \pm 2.15$ & $3.66-14.27$ & $7.41 \pm 1.66$ & $3.85-10.43$ & 0.32 \\
\hline Eminence angle & $38.66 \pm 9.51$ & $18.4-58.9$ & $36.03 \pm 9.85$ & $14.2-34.9$ & 0.9274 \\
\hline Condylar angle & $19.85 \pm 6.52$ & $6.8-31.1$ & $18.69 \pm 8.28$ & $5.0-36.5$ & 0.495 \\
\hline
\end{tabular}

Significant difference $\left({ }^{*} P \leq 0.05\right)$. AJS: Anterior joint space, SJS: Superior joint space, PJS: Posterior joint space, MJS: Medial joint space, LJS: Lateral joint space, SD: Standard deviation

\begin{tabular}{|c|c|c|c|}
\hline \multirow[t]{2}{*}{ Joint space } & \multicolumn{2}{|c|}{ Mean士SD } & \multirow[t]{2}{*}{$P$} \\
\hline & Males (38) & Females (32) & \\
\hline AJS & $2.1 \pm 0.45$ & $2.11 \pm 0.74$ & 0.971 \\
\hline SJS & $5.97 \pm 1.72$ & $4.78 \pm 1.56$ & $0.004^{* *}$ \\
\hline PJS & $6.38 \pm 2.75$ & $5.43 \pm 2.44$ & 0.146 \\
\hline MJS & $5.46 \pm 2.08$ & $5.21 \pm 2.08$ & 0.631 \\
\hline LJS & $3.28 \pm 1.34$ & $2.62 \pm 1.24$ & $0.027^{*}$ \\
\hline P/A & $3.18 \pm 1.59$ & $2.67 \pm 1.52$ & 0.18 \\
\hline S/A & $3.09 \pm 1.4$ & $2.36 \pm 2.18$ & 0.09 \\
\hline$M / L$ & $1.79 \pm 0.8$ & $2.28 \pm 1.35$ & 0.06 \\
\hline A-P distance & $7.49 \pm 1.1$ & $6.58 \pm 1.34$ & $0.004^{* *}$ \\
\hline M-L distance & $18.98 \pm 2.55$ & $15.81 \pm 3.05$ & $0.000^{* *}$ \\
\hline Eminence height & $7.40 \pm 2.27$ & $7.47 \pm 1.48$ & 0.888 \\
\hline Eminence angle & $39.71 \pm 8.58$ & $38.98 \pm 7.94$ & 0.686 \\
\hline Condylar angle & $21.37 \pm 7.86$ & $16.26 \pm 10.13$ & $0.01^{*}$ \\
\hline
\end{tabular}

dimensions of the affected joints when compared with the normal joints. Condylar axial angle, on the other hand, was found to be significantly reduced and became flatter in the affected joints when compared with the normal counterpart $(15.63 \pm 8.46$ vs. $21.19 \pm 6.56)$ as seen in Table 6 . It was found that SJS had direct relationship with PJS, MJS, Eminence and condylar height in normal joints. In joints with TMD, it was found that SJS was directly proportional with PJS, MJS, eminence angle, and height [Table 7].

\section{DISCUSSION}

Radiographically, the joint space is a radiolucent zone. It indicates the area between mandibular condyle and temporal bone. Among all modern imaging modalities, CBCT provides accurate and reliable linear measurements for reconstruction and imaging of almost all maxillofacial structures ${ }^{[13]}$ Degenerative joint 


\begin{tabular}{|c|c|c|c|}
\hline \multirow[t]{2}{*}{ Joint space } & \multicolumn{2}{|c|}{ Mean $\pm S D$} & \multirow[t]{2}{*}{$P$} \\
\hline & Males (30) & Females (40) & \\
\hline AJS & $2.13 \pm 1.06$ & $2.07 \pm 1.00$ & 0.801 \\
\hline SJS & $5.67 \pm 1.87$ & $4.64 \pm 1.69$ & $0.01^{* *}$ \\
\hline PJS & $5.96 \pm 2.95$ & $5.63 \pm 2.13$ & 0.58 \\
\hline MJS & $4.42 \pm 1.62$ & $4.68 \pm 1.92$ & 0.54 \\
\hline LJS & $3.25 \pm 1.66$ & $2.85 \pm 1.15$ & $0.05^{*}$ \\
\hline $\mathrm{P} / \mathrm{A}$ & $2.45 \pm 1.14$ & $3.05 \pm 2.14$ & 0.17 \\
\hline S/A & $2.54 \pm 1.05$ & $2.4 \pm 1.27$ & 0.60 \\
\hline$M / L$ & $1.5 \pm 0.91$ & $1.88 \pm 1.66$ & 0.25 \\
\hline A-P distance & $7.67 \pm 1.39$ & $6.87 \pm 1.32$ & $0.014^{* *}$ \\
\hline M-L distance & $20.8 \pm 2.81$ & $16.51 \pm 2.5$ & $0.000^{* *}$ \\
\hline Eminence height & $8.13 \pm 2.02$ & $7.25 \pm 1.77$ & 0.056 \\
\hline Eminence angle & $39.98 \pm 10.78$ & $35.15 \pm 8.21$ & $0.03^{* *}$ \\
\hline Condylar angle & $20.45 \pm 6.66$ & $18.21 \pm 8.75$ & 0.23 \\
\hline
\end{tabular}

\begin{tabular}{|c|c|c|c|}
\hline \multirow[t]{2}{*}{ Joint space } & \multicolumn{2}{|c|}{ Mean $\pm S D$} & \multirow[t]{2}{*}{$P$} \\
\hline & $\begin{array}{c}\text { Normal } \\
\text { joints (16) }\end{array}$ & $\begin{array}{c}\text { Affected } \\
\text { joints (16) }\end{array}$ & \\
\hline$\overline{\text { AJS }}$ & $1.91 \pm 1.07$ & $1.66 \pm 0.90$ & 0.48 \\
\hline SJS & $4.64 \pm 1.28$ & $6.28 \pm 1.39$ & $0.001^{\text {** }}$ \\
\hline PJS & $5.59 \pm 3.22$ & $6.69 \pm 3.71$ & 0.37 \\
\hline MJS & $3.55 \pm 1.42$ & $4.82 \pm 1.65$ & $0.01^{* *}$ \\
\hline LJS & $3.05 \pm 1.5$ & $3.9 \pm 1.01$ & 0.17 \\
\hline A-P distance & $7.74 \pm 1.3$ & $7.59 \pm 1.75$ & 0.73 \\
\hline M-L distance & $20.02 \pm 2.94$ & $20.92 \pm 2.91$ & 0.39 \\
\hline Eminence height & $8.19 \pm 1.86$ & $7.73 \pm 1.55$ & 0.45 \\
\hline Eminence angle & $30.01 \pm 9.39$ & $40.78 \pm 10.57$ & $0.004^{* *}$ \\
\hline Condylar angle & $23.18 \pm 56.47$ & $18.36 \pm 5.1$ & $0.03^{*}$ \\
\hline
\end{tabular}

disease is one of the conditions that can deteriorate the joint by loss of articular disc and bone erosion. The joint space becomes reduced and irregular, and the articular surface is flattened. All these changes are seen best on tomograms or CT scans. ${ }^{[1]}$ Differential diagnosis for TJD according to its subtypes is considered to be difficult, especially in research due to overlapping of signs and symptoms between different subgroups that will consequently affect the selection of homogenous subject group for research. Thus, it is necessary to make a standardized data collection and instruments to measure the degree of severity of TJD.

In this study, patients were examined and classified according to RDC/TMD index..$^{[12]}$ The present study
Table 6: Paired $t$-test between normal versus affected joints among females

\begin{tabular}{lccc}
\hline Joint space & \multicolumn{2}{c}{ Mean \pm SD } & $P$ \\
\cline { 2 - 3 } & $\begin{array}{c}\text { Normal } \\
\text { joints (18) }\end{array}$ & $\begin{array}{c}\text { Affected } \\
\text { joints (18) }\end{array}$ & \\
\hline AJS & $2.30 \pm 0.88$ & $2.07 \pm 0.979$ & 0.48 \\
SJS & $3.37 \pm 1.87$ & $4.50 \pm 1.68$ & 0.06 \\
PJS & $5.22 \pm 1.24$ & $5.87 \pm 2.33$ & 0.30 \\
MJS & $3.99 \pm 0.93$ & $5.13 \pm 1.72$ & $0.01^{\text {** }}$ \\
LJS & $2.61 \pm 1.08$ & $2.92 \pm 1.21$ & 0.40 \\
A-P distance & $7.11 \pm 1.26$ & $6.20 \pm 1.9$ & 0.09 \\
M-L distance & $17.38 \pm 3.04$ & $16.12 \pm 2.33$ & 0.17 \\
Eminence height & $7.31 \pm 2.27$ & $7.12 \pm 2.10$ & 0.79 \\
Eminence angle & $34.62 \pm 5.91$ & $33.4 \pm 2.33$ & 0.42 \\
Condylar angle & $21.19 \pm 6.56$ & $15.63 \pm 8.46$ & $0.03^{*}$ \\
\hline
\end{tabular}

Significant difference $\left({ }^{*} P \leq 0.05 ;{ }^{* *} P \leq 0.01\right)$. AJS: Anterior joint space, SJS: Superior joint space, PJS: Posterior joint space, MJS: Medial joint space, LJS: Lateral joint space, SD: Standard deviation

\begin{tabular}{|c|c|c|c|c|c|}
\hline $\begin{array}{l}\text { Normal } \\
\text { joints }\end{array}$ & $r$ & PJS & MJS & $\begin{array}{c}\text { Eminence } \\
\text { height }\end{array}$ & $\begin{array}{c}\text { Eminence } \\
\text { angle }\end{array}$ \\
\hline Right side & SJS & $0.765^{\star *}$ & $0.536^{\star *}$ & $0.473^{* *}$ & 0.343 \\
\hline Left side & & $0.790^{* *}$ & $0.554^{* *}$ & 0.289 & 0.187 \\
\hline $\begin{array}{l}\text { Affected } \\
\text { joints }\end{array}$ & $r$ & PJS & MJS & $\begin{array}{c}\text { Eminence } \\
\text { height }\end{array}$ & $\begin{array}{c}\text { Eminence } \\
\text { angle }\end{array}$ \\
\hline Right side & SJS & $0.568^{* * *}$ & $0.462^{* *}$ & $0.501^{* *}$ & $0.475^{\star *}$ \\
\hline Left side & & $0.700^{* *}$ & $0.405^{\star}$ & $0.447^{*}$ & $0.355^{*}$ \\
\hline
\end{tabular}

included patients who had positive responses in dysfunction index; this assessed the presence of joint problems, such as disc displacement with or without reduction. The aim of this study was to evaluate the condylar position in patients with various signs and symptoms of functional joint problems using the normal protocol of patient positioning in CBCT machine. The results of the present study showed a predominance of AJS which was smaller than the posterior space. This result was in accordance with that of Ikeda and Kawamura ${ }^{[8]}$ and contrary to the study of Mazzetto et al. ${ }^{[5]}$ This disagreement could be attributed to the anteriorized condylar position due to edge-to-edge incisal relationship during CBCT imaging which displaces the condyle slightly anteriorly, thus reducing AJS. The comparison between genders showed significant differences in superior and LJS dimensions with males showing greater measurements than females. Similar results were found by Mazzetto et al. ${ }^{[5]}$ and Kinniburgh et al. ${ }^{[14]}$ Evaluating asymptomatic subjects, it was also possible to observe that the values of joint space in this study were greater than that of previous studies. ${ }^{[5,15]}$ This 
difference is mainly due to different protocols used for CBCT imaging. Most previous studies used maximal occlusal intercuspation which was not the same used in normal Sironal CBCT protocols (edge-to-edge incisal relationship). Major et al., ${ }^{[16]}$ Christiansen et al.,$^{[17]}$ and Sicher and Du Brul ${ }^{[18]}$ found an association between disc displacements and changes in the joint space dimensions.

Ikeda and Kawamura evaluated joint spaces on the central cuts of joints within $3.5 \mathrm{~mm}$ range medially and laterally to the central cut in CBCT. ${ }^{[11]}$ However, there is a controversy over the clinical significance of condylar position. Many studies have reported nonconcentric condylar position in association with disc displacement, ${ }^{[8,19]}$ osteoarthritic changes, ${ }^{[7]}$ remodeling of the articular eminence, and the condyle. ${ }^{[20]}$ In the present investigation, it has been found that most normal and affected joints were anteriorly displaced (due to edge-to-edge incisal relationship during CBCT imaging) and this reduces the AJS and increases the posterior and SJS. Nonconcentric condylar positioning is seen in $1 / 3$ to $1 / 2$ of asymptomatic volunteers. ${ }^{[2]}$ On the other hand, concentric positioning in patients with TMD has high prevalence. ${ }^{[21]}$ According to the present study, condylar eccentricity alone is not a sufficient evidence for the diagnosis of TMD. Similarly, many studies have concluded that the presence or absence of TMD was not correlated with condyle position in TMJ. ${ }^{[22,23]}$ In this study, superior and MJS were significantly different when affected joints in comparison with normal counterparts in both genders.

Articular eminence may predispose to disc displacement since the shape of the articular eminence is related to the development of TMJ disc displacement. ${ }^{[19]}$ Some studies found a gender difference in eminence inclination. ${ }^{[24-26]}$ In the present study, eminence inclination was greater in males which are in accordance with other studies. ${ }^{[24,25,27]}$ However, nonsignificant statistical differences in $\mathrm{EH}$ and angle inclination were observed between affected joints and normal counterparts in female groups, but with highly significant increase in eminence inclination in the affected joints of males group.

Westesson et al. ${ }^{[28]}$ found that the mean axial condylar angle was the smallest in joints with a normal TMJ $\left(21.2^{\circ}\right)$ and become larger in affected joints (33.5 $5^{\circ}$ for disc displacement). Compared with prior study, the present investigation revealed an approximate $23.18^{\circ}$ for males and $21.9^{\circ}$ for females with normal joints and $18.36^{\circ}$ for males and $15.36^{\circ}$ for females with affected joints which is exactly opposite to Westesson et al. findings. This may indicate that the condyles of the affected joints rotate inwardly, and this leads to decrease the axial condyle angle.

\section{CONCLUSION}

Superior and MJS parameters were the ones that showed significant differences between affected and nonaffected joints. However, radiographic assessment of condylar joint space alone is not enough to prove or disprove the presence of TMD. The mean axial condylar angle was smaller in joints with abnormal TMJ which indicates that the condyles of the affected joints may rotate inward.

\section{Financial support and sponsorship}

Nil.

\section{Conflicts of interest}

There are no conflicts of interest.

\section{REFERENCES}

1. Hegde S, Praveen BN, Shetty SR. Morphological and radiological variations of mandibular condyles in health and diseases: A systematic review. Dentistry 2013;3:154.

2. Torenek K, Duman SB, Bayrakdar IS, Miloglu O. Clinical and radiological findings of a bilateral coronoid hyperplasia case. Eur J Dent 2015;9:149-52.

3. Pandis N, Karpac J, Trevino R, Williams B. A radiographic study of condyle position at various depths of cut in dry skulls with axially corrected lateral tomograms. Am J Orthod Dentofacial Orthop 1991;100:116-22.

4. Katsavrias EG. Changes in articular eminence inclination during the craniofacial growth period. Angle Orthod 2002;72:258-64.

5. Mazzetto MO, Veneziam GC, Magri LV, Nasr MK, Paiva AF, Paiva G. Evaluation of the condylar position in subjects with signs and symptoms of functional disorders of the temporomandibular joint through images made with cone beam computed tomography on sagittal plane. Braz Dent Sci 2014;17:77-82.

6. Dalili Z, Khaki N, Kia SJ, Salamat F. Assessing joint space and condylar position in the people with normal function of temporomandibular joint with cone-beam computed tomography. Dent Res J (Isfahan) 2012;9:607-12.

7. Cho BH, Jung YH. Osteoarthritic changes and condylar positioning of the temporomandibular joint in Korean children and adolescents. Imaging Sci Dent 2012;42:169-74.

8. Ikeda K, Kawamura A. Assessment of optimal condylar position with limited cone-beam computed tomography. Am J Orthod Dentofacial Orthop 2009;135:495-501.

9. Incesu L, Taskaya-Yilmaz N, Ogütcen-Toller M, Uzun E. Relationship of condylar position to disc position and morphology. Eur J Radiol 2004;51:269-73.

10. Herbosa EG, Rotskoff KS, Ramos BF, Ambrookian HS. Condylar position in superior maxillary repositioning and its effect on the temporomandibular joint. J Oral Maxillofac Surg 1990;48:690-6.

11. O'Ryan F, Epker BN. Surgical orthodontics and the temporomandibular joint. I. Superior repositioning of the maxilla. Am J Orthod 1983;83:408-17.

12. Anderson GC, Gonzalez YM, Ohrbach R, Truelove EL, Sommers E, Look JO, et al. The research diagnostic criteria for temporomandibular disorders. VI: Future directions. J Orofac Pain 2010;24:79-88.

13. Karatas $\mathrm{OH}$, Toy E. Three-dimensional imaging techniques: A literature review. Eur J Dent 2014;8:132-40. 


\section{Al-Rawi, et al:: TMJ space and CBCT}

14. Kinniburgh RD, Major PW, Nebbe B, West K, Glover KE. Osseous morphology and spatial relationships of the temporomandibular joint: Comparisons of normal and anterior disc positions. Angle Orthod 2000;70:70-80.

15. Brooks SL, Brand JW, Gibbs SJ, Hollender L, Lurie AG, Omnell KA, et al. Imaging of the temporomandibular joint: A position paper of the American Academy of Oral and Maxillofacial Radiology. Oral Surg Oral Med Oral Pathol Oral Radiol Endod 1997;83:609-18.

16. Major PW, Kinniburgh RD, Nebbe B, Prasad NG, Glover KE. Tomographic assessment of temporomandibular joint osseous articular surface contour and spatial relationships associated with disc displacement and disc length. Am J Orthod Dentofacial Orthop 2002;121:152-61.

17. Christiansen EL, Chan TT, Thompson JR, Hasso AN, Hinshaw DB Jr., Kopp S. Computed tomography of the normal temporomandibular joint. Scand J Dent Res 1987;95:499-509.

18. Sicher H, Du Brul EL. $5^{\text {th }}$ ed. Sicher's oral anatomy. St. Louis: C. V. Mosby; 1980. p. 158.

19. Kurita H, Ohtsuka A, Kobayashi H, Kurashina K. Flattening of the articular eminence correlates with progressive internal derangement of the temporomandibular joint. Dentomaxillofac Radiol 2000;29:277-9.

20. Scapino RP. Histopathology associated with malposition of the human temporomandibular joint disc. Oral Surg Oral Med Oral Pathol 1983;55:382-97.

21. Markovic MA, Rosenberg HM. Tomographic evaluation of 100 patients with temporomandibular joint symptoms. Oral Surg Oral Med Oral
Pathol 1976;42:838-46

22. Paknahad M, Shahidi S. Association between mandibular condylar position and clinical dysfunction index. J Craniomaxillofac Surg 2015;43:432-6.

23. Lelis ÉR, Guimarães Henriques JC, Tavares M, de Mendonça MR, Fernandes Neto AJ, Almeida Gde A. Cone-beam tomography assessment of the condylar position in asymptomatic and symptomatic young individuals. J Prosthet Dent 2015;114:420-5.

24. Ejima K, Schulze D, Stippig A, Matsumoto K, Rottke D, Honda K. Relationship between the thickness of the roof of glenoid fossa, condyle morphology and remaining teeth in asymptomatic European patients based on cone beam CT data sets. Dentomaxillofac Radiol 2013;42:90929410.

25. Jasinevicius TR, Pyle MA, Lalumandier JA, Nelson S, Kohrs KJ, Türp JC, et al. Asymmetry of the articular eminence in dentate and partially edentulous populations. Cranio 2006;24:85-94.

26. Ishimaru J, Handa Y, Kurita K, Goss AN. The effect of occlusal loss on normal and pathological temporomandibular joints: An animal study. J Craniomaxillofac Surg 1994;22:95-102.

27. Zabarovic D, Jerolimov V, Carek V, Vojvodic D, Zabarovic K, Bukovic D Jr. The effect of tooth loss on the TM-joint articular eminence inclination. Coll Antropol 2000;24 Suppl 1:37-42.

28. Westesson PL, Bifano JA, Tallents RH, Hatala MP. Increased horizontal angle of the mandibular condyle in abnormal temporomandibular joints. A magnetic resonance imaging study. Oral Surg Oral Med Oral Pathol 1991;72:359-63. 